\title{
DEPÓSITOS DE PATENTES E VALOR DE MERCADO: O CASO DA PETROBRÁS
}

\section{PATENT DEPOSITS AND MARKET VALUE: THE CASE OF PETROBRAS}

\author{
Marina Bezerra da Silva \\ Instituto Federal do Piauí - PI / Universidade Federal de Sergipe - UFS \\ marina.silva@ifpi.edu.br \\ Rafael Ângelo Santos Leite \\ Instituto Federal do Piauí - PI / Universidade Federal de Sergipe - UFS \\ rafaelangelo@ifpi.edu.br \\ Suzana Leitão Russo \\ UFPI - Universidade Federal do Piauí - PI \\ suzana.ufs@hotmail.com \\ Iracema Machado de Aragão \\ Universidade Federal de Sergipe - UFS \\ aragao.ufs@gmail.com \\ José Ricardo de Santana \\ Universidade Federal de Sergipe - UFS \\ santana_josericardo@yahoo.com.br
}

Submissão: 30/03/2019

Aprovação: $05 / 10 / 2020$

\section{RESUMO}

Os estudos sobre ativos intangíveis vêm aumentando significativamente devido a sua relevância para a composição do valor da empresa. Considerando que a Petrobras é uma das empresas que mais investe em Ciência e Tecnologia no setor petrolífero brasileiro e tem fortes parcerias com instituições de pesquisa no desenvolvimento de novos conhecimentos e tecnologias, este estudo examina a relação entre depósitos de patentes e valor de mercado da referida empresa entre 1996 e 2015. Análises de regressão linear múltipla permitiram observar o comportamento do valor de mercado a partir de depósitos de patentes e do rating (nível de risco da empresa) durante uma serie temporal. Os resultados evidenciam que a estratégia de efetuar depósitos de patentes na Petrobras não interferiu em seus desempenhos de mercado no período analisado.

Palavras-chave - Ativos intangíveis, Valor de mercado, Depósitos de patentes, Petrobras. 


\begin{abstract}
The studies on intangible assets are increasing significantly due to their relevance to the composition of the company's value. Considering that Petrobras is one of the companies that most invests in Ciência e Tecnologia, which is not a Brazilian oil company and has partnerships with research institutions and no development of new knowledge and technologies, this study examines the relationship between patent deposits and the market value of the aforementioned company between 1996 and 2015. Multiple linear regression analyzes allow observing the market value behavior from patent deposits and rating (company risk level) during a time series. The results show that the strategy of filing patents with Petrobras does not interfere with their market performance in the period analyzed.
\end{abstract}

Keywords - Intangible assets, Market value, Patent deposits, Petrobras.

\title{
1 INTRODUÇÃO
}

A inovação é o motor dos ganhos de produtividade no longo prazo. A ampliação da capacidade de inovação é fator crítico para a melhoria da competitividade empresarial. Para isso, "uma política industrial e de inovação consistente é fundamental" no ambiente de empresas (CNI, 2018, p. 144). Nesse contexto, cabe às organizações buscarem o lançamento de novos e melhores produtos e modelos de negócio, além de melhoria contínua nos processos fabris e de gestão. Isso torna-se ainda mais relevante quando se considera que o investimento em inovação gera benefícios para toda a economia (CNI, 2018).

O lançamento de novos produtos ou processos exige prévios investimentos em novos conhecimentos, em pesquisa e desenvolvimento e na proteção de ativos criados através de direitos de propriedade intelectual. Não é à toa que o valor das empresas intensivas em conhecimento é determinado pelo valor da sua propriedade intelectual (HANEL, 2006). As empresas modernas têm percebido que a criação de valor baseia-se na economia dos intangíveis, e é "regida pela aquisição de conhecimento e informação" (SANTOS, 2015, p. 101).

Os estudos sobre esse tema podem ser divididos em dois grupos, não havendo ainda uma zona de convergência sobre a relação inovação e desempenho. Para um grupo de autores, há uma relação positiva e significativa entre a contagem de patentes e a qualidade destas com o valor de mercado das empresas (SANDNER; BLOCK, 2011/9; DENG; LEV; NARIN, 1999; LEITE; SANTOS, 2013; MAZZIONI et al., 2014; SANTOS, 2015). Para outro grupo de estudos, os resultados apresentam uma relação neutra ou negativa (LAZZAROTTI; JUNIOR; FISCHER, 2011; CARMONA; ZONATTO, 2017; RITTA; CUNHA; KLANN, 2017).

Partindo destes estudos prévios e considerando que as pesquisas sobre ativos intangíveis vêm aumentando significativamente em função da relevância destes recursos para a composição do valor da empresa (NASCIMENTO et al., 2012), este estudo tem o objetivo de verificar a relação entre depósitos de patentes e valor de mercado de uma empresa do ramo Petróleo e Gás, especificamente a Petrobras (Petróleo Brasileiro S.A.) entre os anos de 1996 e 2015.

Visto que o movimento em prol da convergência às práticas contábeis internacionais tem exigido "das empresas a identificação, mensuração, reconhecimento e divulgação dos ativos intangíveis" (SANTOS, 2015, p. 101), este estudo justifica-se pela necessidade de entender se existe realmente influência da PI (propriedade intelectual) sobre o valor de mercado de indústrias fortes, como a petrolífera. Isso torna-se ainda mais relevante quando se constata que o setor 
produtivo interno ainda necessita de muita tecnologia, o que pode ser medido pelo déficit tecnológico, que em 2011 ficou em US\$ 23 bilhões. Além disso, o setor de refino de petróleo está entre os que mais demandaram tecnologia nesse período (SILVA, 2013, p. 52).

\section{REVISÃO DE LITERATURA E HIPÓTESE DE PESQUISA}

Esta seção apresenta uma revisão de literatura sobre propriedade intelectual e desempenho, além de relatar algumas características dessa relação no setor de petróleo e gás. Isso é feito a fim de formular a hipótese desta pesquisa.

\subsection{PROPRIEDADE INTELECTUAL E DESEMPENHO}

Os estudos sobre inovação, propriedade intelectual e desempenho econômico-financeiro vêm sendo recorrentes na literatura (DENG; LEV; NARIN, 1999; LAZZAROTTI; JUNIOR; FISCHER, 2011; NASCIMENTO et al., 2012; LEITE; SANTOS, 2013; MAZZIONI et al., 2014; CARMONA; ZONATTO, 2017; RITTA; CUNHA; KLANN, 2017).

Há presença de diversas relações estatisticamente significativas, mostrando a influência do grau de intangibilidade das empresas no desempenho econômico (MAZZIONI et al., 2014). Nascimento et al. (2012) verificaram que existe correlação entre o Grau de Intangibilidade (GI) e os indicadores de desempenho das empresas dos setores de tecnologia da informação e de telecomunicações. Outros estudos, com foco em marcas, indicam que tanto os ativos de conhecimento como as marcas comerciais são economicamente valorizados no mercado de ações, uma vez que estão positivamente associados ao valor da empresa (SANDNER; BLOCK, 2011/9).

O grau de intangibilidade (GI) interferiu no desempenho econômico das amostras pesquisadas por Mazzioni et al., (2014), apresentando relações estatisticamente significativas no período investigado com ROA (rentabilidade do ativo) e ROE (rentabilidade do patrimônio líquido). Os resultados indicam que a presença dos intangíveis melhora o desempenho organizacional. Apesar do avanço no reconhecimento contábil dos ativos intangíveis, é possível que a parte gerada internamente e não reconhecida nas demonstrações contábeis, seja um fator importante de impulso do desempenho organizacional (MAZZIONI et al., 2014).

Examinando os documentos de registro de patentes (nos Estados Unidos) durante os anos de 1985 e 1995, Deng, Lev e Narin (1999) estudaram a influência das patentes sobre o valor das empresas. Seus resultados mostraram uma relação positiva e significativa entre a medida de valor de mercado e a quantidade de patentes concedidas por ano à empresa, a quantidade de citações que essas patentes receberam de patentes subsequentes, bem como o número de referências científicas registradas nessas patentes (DENG; LEV; NARIN, 1999).

Utilizando a técnica do MVA (Market Value Added) para valorar os intangíveis das empresas, a partir da identificação do valor econômico adicionado (EVA) e do custo da estrutura de capital das empresas (WACC), além de uma análise de regressão com dados em painel, Leite e Santos (2013) estudaram o relacionamento entre os ativos intangíveis e valor de mercado. Os resultados confirmam que os intangíveis exercem influência positiva no desempenho das empresas.

Os ativos intangíveis podem provocar diferenças entre as empresas em relação ao retorno, podendo ser essa uma consequência derivada de vantagens competitivas presentes nas firmas consideradas como intangível-intensivas. Os resultados da pesquisa sugerem que o investimento 
representativo dos intangíveis reconhecidos pode interferir na percepção do mercado, causando reflexos no valor das firmas (SANTOS, 2015, p. 101). "Os investidores compreenderam que nas organizações com proporção patrimonial intangível majoritária há maior chance de concretização de desempenhos anormais devido às chances de se conseguir vantagens sustentáveis oriundas do capital não tangível" (SANTOS, 2015, p. 101).

Há, porém, estudos contraditórios, que apresentam resultados inconclusivos, e que não demonstram relações positivas entre propriedade intelectual, inovação e desempenho.

Analisando a relação do número de patentes concedidas e o desempenho econômicofinanceiro e de mercado das empresas listadas na BM\&FBOVESPA (Bolsa de Valores, Mercadorias e Futuros de São Paulo), no período de 2000 a 2009, Lazzarotti et al. (2011) entenderam não ser possível afirmar, conclusivamente, que o desempenho é afetado pelas patentes outorgadas, sendo estas consideradas um excelente indicador do conhecimento científico, mas não parecem ser capazes de impulsionar o desempenho econômico-financeiro e de mercado das empresas (LAZZAROTTI; JUNIOR; FISCHER, 2011).

Carmona e Zonatto (2017) estudaram as empresas listadas na bolsa brasileira, presentes no ranking de inovação da Strategy e analisam se o número de patentes concedidas, número de produtos novos, despesas com P\&D (pesquisa e desenvolvimento), unidades de pesquisa, quantidade de funcionários envolvidos com $\mathrm{P} \& \mathrm{D}$, parcerias, ranking de inovação e setor afetam o desempenho da firma, mensurado pela receita total e pelo EBITDA (Earnings before interest, taxes, depreciation and amortization). Verificaram via análise em painel que apenas o investimento em pesquisa e desenvolvimento, parcerias realizadas e setor de atuação afetam a receita total empresarial. O EBITDA não se mostrou influenciável pela inovação (CARMONA; ZONATTO, 2017).

Ritta, Cunha e Klann (2017) observaram a influência entre investimentos em ativos intangíveis e desempenho empresarial de empresas listadas na BM\&FBOVESPA de 2010 a 2014. Usando Teste de Causalidade de Granger, verificaram que na maioria das empresas não há relação de causalidade entre ativos intangíveis e indicadores de desempenho econômicofinanceiro. Numa pequena quantidade de empresas, entretanto, os ativos intangíveis causam impactos no desempenho financeiro. Assim, os autores concluíram que investimentos em ativos intangíveis podem não aparecer no curto prazo no desempenho. Entretanto, podem representar vantagens competitivas que geram efeitos ao longo do tempo (RITTA; CUNHA; KLANN, 2017).

Conclui-se, portanto, que a literatura apresenta resultados contraditórios, indicando a existência de correlação em determinados segmentos e inexistência para outros.

\subsection{A PETROBRAS E VALOR DE MERCADO}

A Petrobras foi criada em 1953 pelo governo federal brasileiro e é, desde então, uma das maiores empresas do Brasil. Em 2007 foi considerada, pelo Reputation Institute, "a empresa com maior valor de mercado da América Latina e a oitava empresa mais respeitada do mundo" (ALMEIDA et al., 2008, p. 6).

É considerada um grande player no mercado internacional na indústria de petróleo e gás antes do refino, particularmente em operações de águas profundas e ultraprofundas, porém apesar do fato de que as reservas do pré-sal foram descobertas pela Petrobras, não houve um aumento nos pedidos de patentes após o anúncio do pré-sal. Fato contrário ocorreu em outras multinacionais que operam na indústria de petróleo e gás, onde a descoberta de pré-sal afetou significativamente suas estratégias de patentes, gerando assim um boom em documentos de 
patente no Brasil, do anúncio oficial do pré-sal em diante (CAVALHEIRO; JOIA, 2014).

Em meados do ano de 2002, tinha um valor de mercado de aproximadamente $\mathrm{R} \$ 54,0$ bilhões, mas alcançou ao final do ano de 2007 a expressiva cifra de R \$ 430,0 bilhões, ano do anúncio da descoberta do Pré-Sal. Infelizmente, nos últimos anos (a partir de 2010), esteve "excessivamente exposta a fatores relacionados a riscos sistêmicos e não sistêmicos, bem como, problemas de governança corporativa associados ao excesso de interferência governamental em sua gestão e a escândalos políticos e casos de corrupção" (GODOI; SANTOS, 2018, p. 310).

A Petrobras é atualmente uma das empresas que mais investe em Ciência e Tecnologia no setor petrolífero brasileiro. Grande parte da estratégia corresponde a parcerias com ICTs (Instituições de Ciência e Tecnologia) e universidades. Um importante recurso é o CENPES (Centro de Pesquisas e Desenvolvimentos), que funciona desde 1963, e que desde 1973, está no campus da Universidade Federal do Rio de Janeiro (UFRJ), sendo o órgão responsável pelo sistema tecnológico da empresa. A estratégia principal de atuação corresponde à geração de novas tecnologias, produtos, processos e de spin-offs (FERREIRA; RAMOS, 2017).

Uma importante estratégia implantada na empresa foram as parcerias com universidades para criação das Redes Temáticas e dos Núcleos Regionais de Competência. Estes projetos têm a finalidade de trabalhar em pesquisas e em busca de soluções para a empresa (FERREIRA; RAMOS, 2017).

Com base nesta revisão de literatura sobre questões associadas à relação entre desempenho (valor de mercado) e depósito/registro de propriedade intelectual no contexto da indústria brasileira de petróleo e gás, foi formulada a seguinte hipótese de pesquisa, testada neste estudo:

H1: A estratégia de depositar patentes da empresa Petrobras interfere em seu valor de mercado.

\section{METODOLOGIA}

Esta pesquisa caracterizou-se como um estudo descritivo de abordagem quantitativa e visou analisar a relação entre desempenho de mercado, depósitos de patentes e nível de risco no setor petrolífero brasileiro. Para isso, foi observada a empresa Petrobrás durante a série temporal de 1996 até 2015. Esta empresa foi escolhida por ser um dos maiores grupos empresariais do país e do mundo no setor petrolífero (GODOI; SANTOS, 2018).

Os dados utilizados referem-se ao logaritmo do valor de mercado, ao quantitativo de patentes depositadas e ao nível de risco (rating) ao longo do período analisado. Os dados foram coletados através das bases Economática e do Instituto Nacional de Propriedade Industrial (INPI), além do próprio site da Petrobrás. A análise e tratamento foi realizada por meio do software SPSS. O Quadro 1 apresenta as variáveis do estudo:

Quadro 1 - Variáveis analisadas

\begin{tabular}{|c|c|c|c|c|}
\hline Variáveis & $\begin{array}{c}\text { Tipo de } \\
\text { variável }\end{array}$ & Descrição & Base & Fonte \\
\hline $\begin{array}{c}\text { Valor de } \\
\text { mercado } \\
(\mathrm{VM})\end{array}$ & $\begin{array}{c}\text { Dependente } \\
\text { (financeira) }\end{array}$ & $\begin{array}{c}\text { Multiplicação entre a } \\
\text { quantidade de ações } \\
\text { negociadas de uma } \\
\text { firma e o valor de }\end{array}$ & Economática & (LIMA et al., 2014) \\
\hline
\end{tabular}




\begin{tabular}{|c|c|c|c|c|}
\hline $\begin{array}{c}\text { Depósitos de } \\
\text { patentes } \\
\text { (PAT) }\end{array}$ & $\begin{array}{c}\text { Independente } \\
\text { (propriedade } \\
\text { intelectual) }\end{array}$ & $\begin{array}{c}\text { Quantidade acumulada } \\
\text { de patentes depositadas } \\
\text { pela empresa. }\end{array}$ & INPI & $\begin{array}{c}\text { (SANDNER; } \\
\text { BLOCK, 2011/9; } \\
\text { CARMONA; } \\
\text { ZONATTO, 2017) }\end{array}$ \\
\hline $\begin{array}{c}\text { Rating } \\
\text { (RAT) }\end{array}$ & $\begin{array}{c}\text { Controle } \\
\text { (financeira) }\end{array}$ & $\begin{array}{c}\text { Grau de risco do } \\
\text { investimento em ações } \\
\text { da empresa. }\end{array}$ & $\begin{array}{c}\text { (PETROBRAS, } \\
\text { 2018) }\end{array}$ & (RIBAS, 2007) \\
\hline
\end{tabular}

Fonte: dados da pesquisa (2018).

Para a variável valor de mercado, foi calculado o logaritmo natural, visando-se a normalização dos resíduos da regressão, pressuposto metodológico das regressões lineares múltiplas (FÁ VERO et al., 2009).

Em relação ao rating da Petrobras, identificaram-se os graus de risco de 1998 até 2016, conforme avaliação realizada pela agência de classificação Moody's (PETROBRAS, 2018). Não foram identificadas as classificações de risco de 1996 e de 1997 (primeiros anos da série histórica desse estudo). Neste sentido, para operacionalização da pesquisa, foram atribuídos os mesmos ratings de 1998 nos dois anos supracitados.

Para tabulação desses dados, montou-se uma escala do rating (Moody’s) variando de 1 a 21 (Quadro 2), conforme o nível de risco da empresa. A seguir, apresenta-se a escala:

Quadro 2 - Escala do Rating

\begin{tabular}{|c|c|c|c|c|c|c|c|c|c|c|}
\hline AAA & Aa1 & $\mathbf{A a} 2$ & $\mathbf{A a 3}$ & $\mathbf{A 1}$ & $\mathbf{A 2}$ & $\mathbf{A 3}$ & $\mathbf{B a a} 1$ & Baa2 & Baa3 & Ba1 \\
\hline 01 & 02 & 03 & 04 & 05 & 06 & 07 & 08 & 09 & 10 & 11 \\
\hline Ba2 & $\mathbf{B a 3}$ & $\mathbf{B 1}$ & $\mathbf{B 2}$ & $\mathbf{B 3}$ & $\mathbf{C a a} 1$ & $\mathbf{C a a} 2$ & $\mathbf{C a a 3}$ & $\mathbf{C a}$ & $\mathbf{C}$ & - \\
\hline 12 & 13 & 14 & 15 & 16 & 17 & 18 & 19 & 20 & 21 & - \\
\hline
\end{tabular}

Fonte: dados da pesquisa (2018).

Este estudo buscou analisar o valor de mercado a partir dos depósitos de patentes e do nível de risco atribuído à Petrobrás ao longo dos últimos 20 anos. Estimou-se, assim, o valor de mercado da Petrobrás a partir da intensidade de patenteamento de tecnologias e inovações, bem como grau de risco do investimento na empresa.

Destaca-se que a empresa em estudo tem grande impacto estratégico para o Brasil. Além disso, tem investido bastante em P\&D e na formalização de sua propriedade intelectual, o que reflete no grande quantitativo de patentes e de marcas depositadas e protegidas perante o INPI.

A pesquisa foi operacionalizada através de uma regressão linear múltipla (FÁVERO et al., 2009), em que se observou o comportamento do valor de mercado a partir de depósitos de patentes e do rating da Petrobras. A hipótese $\mathrm{H} 1$ foi analisada por meio do modelo proposto na Equação 1, a seguir:

$$
\log V M=A+B 1 \cdot P A T+B 2 \cdot R A T+u
$$


Neste modelo, $\log V M$ corresponde ao valor de mercado logaritmizado, sendo a variável dependente do estudo. $A 1$ é o intercepto (constante) da Equação 1. B1 e $B 2$ correspondem aos coeficientes angulares das variáveis independentes (PAT e RAT), respectivamente. PAT é a variável independente da pesquisa, correspondendo ao quantitativo acumulado de patentes depositadas pela empresa. RAT é uma variável controle e indica o grau de risco do investimento na Petrobras. $\mathrm{O} u$ é o termo de erro do modelo.

Com esse modelo, o valor de mercado da Petrobras foi analisado a partir dos depósitos acumulados de patentes e do grau de risco no investimento na empresa. Com esse tipo de análise possibilita-se maior compreensão sobre o modo como a propriedade intelectual tem afetado o desempenho de mercado empresarial no setor petrolífero ao longo dos anos.

Ressalta-se ainda que a estimativa passou por vários testes, dentre os quais: teste de normalidade dos resíduos, teste de Durbin-Watson, testes VIF, teste de tolerância, entre outros.

\section{ANÁLISE DE DADOS}

Nesta seção serão discutidos os resultados da análise entre valor de mercado, depósitos de patentes e rating da empresa Petrobras ao longo dos anos 1996 a 2015.

Inicialmente verificou-se a estatística descritiva dos dados utilizados, conforme a Tabela 1.

Tabela 1 - Estatística descritiva das variáveis

\begin{tabular}{cccccc}
\hline Variável & Média & $\begin{array}{c}\text { Valor } \\
\text { Máximo }\end{array}$ & $\begin{array}{c}\text { Valor } \\
\text { Mínimo }\end{array}$ & $\begin{array}{c}\text { Desvio } \\
\text { Padrão }\end{array}$ & $\begin{array}{c}\text { Quantidade de } \\
\text { Observações }\end{array}$ \\
\hline Log VM & 11,28 & 11,85 & 10,52 & 0,35 & 20 \\
Patentes (acumulado) & 49,65 & 158,0 & 2,0 & 43,51 & 20 \\
Rating & 10,55 & 15 & 7,0 & 2,91 & 20 \\
\hline
\end{tabular}

Fonte: dados da pesquisa (2018).

Mediante a Tabela 1, percebe-se que a empresa foi analisada ao longo de 20 anos. Foram coletadas e analisadas as variáveis logaritmo do valor de mercado, depósitos de patentes e rating. Ao longo do período analisado, o log do valor de mercado médio foi de 11,28, com valor máximo de 11,85 e mínimo de 10,52. O rating esteve numa faixa de risco próxima a 11, com risco mínimo de 7 e máximo de 15. No início do período (1996) a Petrobras tinha 02 (duas) patentes depositadas no INPI, enquanto em 2015 tinha 158 depósitos efetuados.

Nos gráficos 1 e 2, verificam-se o panorama evolutivo dos níveis de classificação de risco da Petrobrás (Gráfico 1) e o panorama evolutivo dos depósitos de patentes (Gráfico 2) entre 1996 e 2018. Ressalta-se que o Gráfico 1 não apresenta os anos de 1996 e 1997, mediante ausência dos dados, conforme explicado na seção metodológica.

Gráfico 1 - Panorama evolutivo dos níveis de classificação de risco da Petrobrás. 


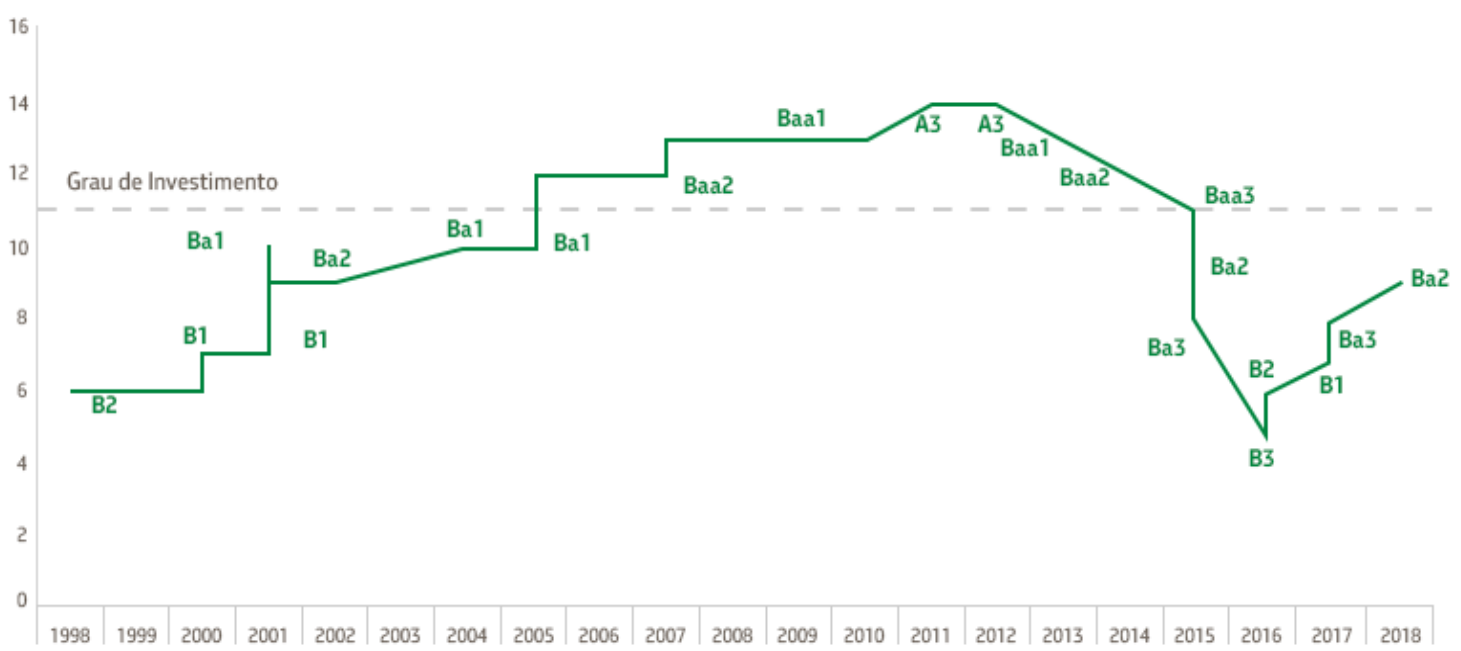

Fonte: Petrobras (2018).

Gráfico 2 - Panorama evolutivo dos depósitos de patentes da Petrobras 1996-2015.

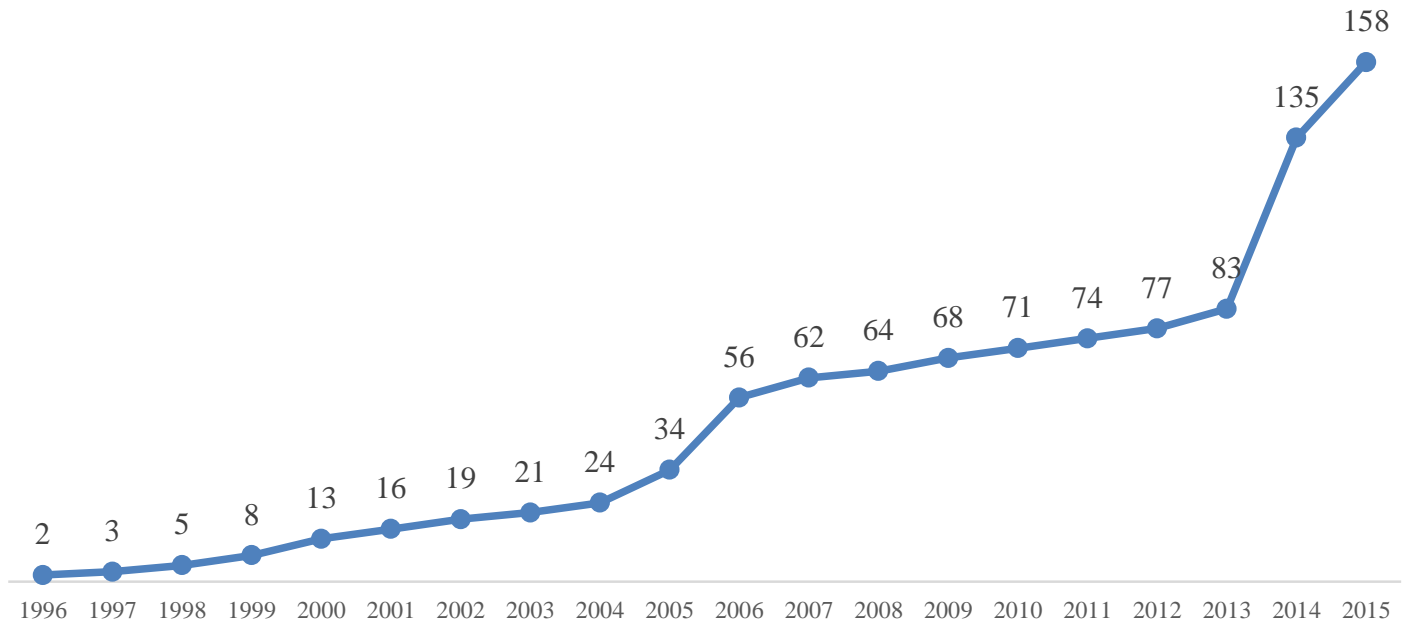

Fonte: dados da pesquisa (2018)

Para analisar melhor a relação entre valor de mercado, depósitos de patentes e nível de risco, neste estudo, foi plotada e analisada uma regressão linear múltipla entre logaritmo do valor de mercado, depósitos de patentes acumulados e rating apresentado nos anos 1996 e 2015. A Tabela 2, a seguir, apresenta as estimativas e resultados dos testes de hipóteses efetuados por meio da regressão.

Tabela 2 - Estimativa da relação entre Ln de valor de mercado, depósitos acumulados de patentes e rating da Petrobras. 


\begin{tabular}{cc}
\hline Variável independente & $\log$ VM $(\%)$ \\
\hline Intercepto & $12,874^{* * *}$ \\
& $(0,243)$ \\
& 0,000 \\
Patentes (depósitos acumulados) & $-0,003^{* *}$ \\
& $(0,001)$ \\
Rating & 0,017 \\
& $-0,135^{* * *}$ \\
R de Pearson & $(0,018)$ \\
R & 0,000 \\
Erro Padrão & 0,89 \\
$\mathrm{~N}^{\circ}$ de observações & 0,79 \\
P-Valor & 0,17 \\
& 20 \\
\hline
\end{tabular}

Nota: Os valores entre parênteses referem-se aos desvios-padrões das estimativas. Os valores em itálico referem-se aos resultados dos testes t efetuados sobre cada variável. Os símbolos $(* * *)$ e (**) indicam, respectivamente, significâncias aos níveis de $1 \%$ e $5 \%$.

Fonte: dados da pesquisa (2018)

Ao se analisar o modelo, verificou-se que o valor de mercado da Petrobras não foi afetado pelo quantitativo de patentes depositadas pela empresa ao longo dos anos analisados. Entretanto, tem sido impactado pelo grau de risco (rating) atribuído às suas atividades operacionais e financeiras.

Identificou-se que o aumento de $100 \%$ no quantitativo de depósitos de patentes gerou alteração de apenas $0,3 \%$ negativos no valor de mercado da empresa. Essa é uma alteração quase insignificante quando se consideram os valores trabalhados (na ordem de bilhões). Assim, entende-se que o valor de mercado e a proteção de patentes, na empresa em estudo, não tem relacionamento econométrico, ou seja, a propriedade intelectual do tipo patentes não tem gerado impactos sobre o valor de mercado da empresa.

Resultados similares foram encontrados em Lazzarotti, Junior e Fischer (2011), Carmona e Zonatto (2017) e Ritta, Cunha e Klann (2017), que não encontram resultados conclusivos sobre relação valor de mercado e depósitos de patentes. Estes autores explicam que no Brasil ainda há baixa quantidade de investimentos em ciência, tecnologia e inovação. Assim, estes aspectos de inovação e de propriedade intelectual ainda não estão difundidos suficientemente a ponto de gerar valor de mercado em curto prazo nas empresas brasileiras.

Além disso, o pequeno entendimento sobre propriedade intelectual, pela sociedade e pelos stakeholders empresariais, fazem com que o mercado pouco compreenda a política de inovação da empresa enquanto recurso estratégico. Isso faz com que o valor de mercado apresente o comportamento identificado neste estudo. Apesar da harmonia com tais estudos, não se pode ignorar que outras explicações podem ser encontradas num cenário de incertezas e de expectativas pouco favoráveis a respeito do futuro da companhia a partir de 2010, o que também "refletiu diretamente na desvalorização do preço das ações negociadas pela empresa em Bolsas de Valores" (GODOI; SANTOS, 2018, p. 311) 
A outra variável analisada foi o rating, que indica o grau de risco do investimento em determinada empresa. Conforme o esperado, o aumento do rating (risco) faz com que a empresa reduza seu valor de mercado. Essas evidências são extremamente importantes. Há uma tendência em investidores/acionistas venderem suas participações em empresas mediante aumento do risco do investimento. Isso faz com que ações tenham valor reduzido, ocasionando queda no valor de mercado empresarial.

O modelo proposto na Tabela 2 apresentou-se significativo ao nível de $1 \%$. Ressalta-se ainda o coeficiente $\mathrm{R}^{2}$, que indica que o modelo estimado tem explicado $79 \%$ da performance do logaritmo do valor de mercado ao longo do período em estudo.

A partir destes resultados, rejeitou-se a hipótese $\mathrm{H} 1$ deste estudo, que afirma que a estratégia de depositar patentes da empresa Petrobras interfere em seu desempenho de mercado. Assim, não há interferência no desempenho de mercado da empresa mediante a realização de depósitos de patentes.

Esse resultado deve ser observado com cautela, pois mostra apenas um período de tempo, sem levar em conta o contexto político-econômico da empresa.

\section{CONSIDERAÇÕES FINAIS}

Nesta última seção, apresentam-se as reflexões sobre a hipótese de pesquisa, as contribuições e implicações deste trabalho, bem como algumas recomendações para novos estudos neste campo.

Este trabalho visou analisar o impacto do depósito de patentes sobre o desempenho de mercado na empresa Petrobras entre os anos 1996 e 2015.

Assim como nos achados de Lazzarotti, Junior e Fischer (2011), Carmona e Zonatto (2017) e Ritta, Cunha e Klann (2017), os resultados desta pesquisa, inconclusivos, sugeriram não haver influência da realização de depósitos de patentes sobre o desempenho empresarial.

Isso pode estar relacionado à pequena difusão da importância da cultura de propriedade intelectual e de inovação entre empresas e players de mercado, o que ocasiona baixos investimentos em ciência, tecnologia e processos de inovação. Além disso, há pequena compreensão sobre propriedade intelectual dentre a comunidade investidora em empresas de capital aberto, o que faz com que esse fator (propriedade intelectual) não seja analisado como diferencial para o desempenho empresarial, e assim, não gere valor superior.

Encontrou-se evidências empíricas que demonstram a importância do planejamento da política de inovação tecnológica e propriedade intelectual da indústria analisada, incentivando a proteção daquelas tecnologias que tiverem importância operacional e estratégica para as atividades da empresa. Além disso, outro fator importante é a política de divulgação do investimento em inovação para os players de mercado, fazendo com que acionistas e demais stakeholders reconheçam e entendam a postura de inovação e a estratégia da empresa.

Este trabalho apresentou algumas limitações em sua operacionalização, como a análise de apenas uma empresa do setor petrolífero e o estudo de uma série de apenas vinte anos. Além disso, não foram analisadas outras variáveis controle que buscassem avaliar o efeito dos problemas de gestão sofridos pela Petrobrás nos últimos anos. Assim, é possível que outros fatores não mensurados neste trabalho também tenham afetado o valor de 
mercado da companhia.

Em pesquisas futuras, recomenda-se a análise de desempenho e de propriedade intelectual considerando-se outras variáveis, como o investimento em pesquisa e desenvolvimento (P\&D), por exemplo. Além disso, sugere-se a análise através de outras abordagens metodológicas. Adicionalmente, seria importante o uso de séries históricas maiores, assim como a avaliação de outras empresas de capital aberto.

\section{REFERÊNCIAS}

ALMEIDA, N. S. de; MARTINS, V. F.; ALMEIDA, L. S. de; SOARES, M. J. F. A utilização da Demonstração do Valor Adicionado na análise da produção e distribuição de riqueza entre os stakeholders: um estudo de caso da Petrobras. In: Anais do Congresso Brasileiro de Custos-ABC, Curitiba. Anais... In: XV CONGRESSO BRASILEIRO DE CUSTOS. Curitiba: 2008. Disponível em: <https://anaiscbc.emnuvens.com.br/anais/article/view/1258>.

CARMONA, L. J. de M.; ZONATTO, V. C. S. Inovação e Desempenho EconômicoFinanceiro de Empresas Brasileiras de Capital Aberto. Caderno Profissional de Administração, v. 7, n. 1, p. 25-44, 2017.

CAVALHEIRO, G. M. C.; JOIA, L. A. Strategic patenting in the upstream oil and gas industry: Assessing the impact of the pre-salt discovery on patent applications in Brazil. World Patent Information, 2014. Disponível em: <http://www.sciencedirect.com/science/article/pii/S0172219014000477>.

CNI. Confederação da Indústria Nacional. Mapa Estratégico da Indústria. Brasília: Confederação Nacional da Indústria. 2018.

DENG, Z.; LEV, B.; NARIN, F. Science and technology as predictors of stock performance. Financial Analysts Journal, 1999. Disponível em: <http://www.cfapubs.org/doi/abs/10.2469/faj.v55.n3.2269>.

DUTRA, A. V.; SCHNORRENBERGER, D.; REINA, D. Mensuração dos ativos intangíveis: uma análise a partir da diferença entre o valor de mercado e patrimonial de empresas listadas na BM\&F BOVESPA no período de 2003 a 2008. Enfoque, v. 28, n. 3, p. 51-68, 2010.

FÁVERO, L. P.; BELFIORE, P.; DILVA, F. L.; CHAN, B. L. Análise de dados: modelagem multivariada para tomada de decisões. Rio de Janeiro: Elsevier, 2009.

FERREIRA, M. L. A.; RAMOS, R. R. Redes e parcerias tecnológicas no setor petrolífero brasileiro: o caso da Petrobras. Revista Espacios, v. 38, n. 32, p. 1-14, 2017.

GODOI, A. F. de; SANTOS, J. O. dos. Contrariando Os Fundamentos de Finanças Corporativas: Análise Da Destruição de Valor Na Petrobras a Partir de 2010. Revista Científica Hermes - FIPEN, v. 21, n. 0, p. 295-315, 31 maio 2018. . Acesso em: 19 jul. 2018.

LAZZAROTTI, A. F.; JUNIOR, S. S.; FISCHER, A. Patentes e Desempenho: um Estudo das Empresas Listadas na BMF BOVESPA com Patentes Concedidas na Década de 2000. In: XXXV Encontro da AMPAD, Anais... In: XXXV ENAMPAD. AMPAD, 2011. 
LEITE, T. S.; SANTOS, D. F. L. A relação dos ativos intangíveis e o valor de mercado na indústria de materiais básicos do Brasil. Revista Brasileira de Administração Científica, v. 4, n. 1, p. 104-121, 14 ago. 2013. . Acesso em: 9 jul. 2017.

LIMA, A. de; TELES, J.; BORNIA, A. C.; FRAZZON, L. S. Relação entre a intangibilidade e o desempenho econômico em empresas brasileiras de capital aberto. In: XXI Congresso Brasileiro de Custos, São Leopoldo - RS. Anais... In: XXI CONGRESSO BRASILEIRO DE CUSTOS. São Leopoldo - RS: Associação Brasileira de Custos, 2014. Disponível em: <http://anaiscbc.emnuvens.com.br/anais/article/view/3854>.

MAZZIONI, S.; RIGO, V. P.; KLANN, R. C.; SILVA JÚNIOR, J. C. A. A relação entre a intangibilidade eo desempenho econômico: Estudo com empresas de capital aberto do Brasil, Rússia, Índia, China e África do Sul (BRICS). Advances in Scientific, 2014. Disponível em: <http://www.asaa.anpcont.org.br/index.php/asaa/article/view/138>.

NASCIMENTO, E. M.; CERQUEIRA, M. de O.; MARQUES, V. A.; CUNHA, J. V. A. da. Ativos intangíveis: análise do impacto do grau de intangibilidade nos indicadores de desempenho empresarial. Enfoque, v. 31, n. 1, p. 37-52, 2012.

PETROBRAS. Rating. Disponível em: <http://www.investidorpetrobras.com.br/pt/divida/rating>. Acesso em: Julho 16, 2018.

RIBAS, L. B. Classificação de risco: caso Petrobras, 2007. . Disponível em: <http://dx.doi.org/10.17771/pucrio.acad.11372>.

RITTA, C. de O.; CUNHA, L. C.; KLANN, R. C. Um Estudo Sobre Causalidade Entre Ativos Intangíveis e Desempenho Econômico de Empresas (2010 - 2014). Revista de Contabilidade do Mestrado em Ciências Contábeis da UERJ (online), v. 22, n. 2, p. 92-107, 2017.

SANDNER, P. G.; BLOCK, J. The market value of R\&D, patents, and trademarks. Research policy, v. 40, n. 7, p. 969-985, 2011/9.

SANTOS, J. G. C. D. Evidências dos Ativos Intangíveis no Contexto Brasileiro: Representatividade, Caracterização, Percepção de Mercado e Desempenho. Revista Contabilidade e Controladoria, v. 7, n. 3, 15 dez. 2015. Disponível em: <http://revistas.ufpr.br/rcc/article/view/38931>.

SILVA, L. C. S. Processo de transferência de tecnologia entre universidade-indústria por intermédio dos núcleos de inovação tecnológica. Universidade Tecnológica Federal do Paraná. 2013. 